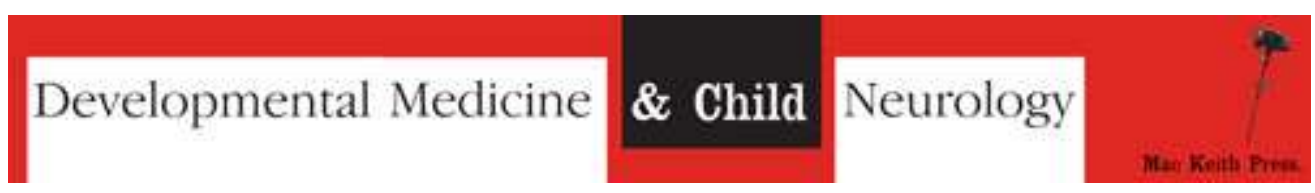

\title{
Enabling self-directed computer use for individuals with cerebral palsy: a systematic review of available assistive devices and technologies.
}

\begin{tabular}{|r|l|}
\hline Journal: & Developmental Medicine \& Child Neurology \\
\hline Manuscript ID: & DMCN-RE-09-04-0196.R2 \\
\hline Danuscript Type: & Review \\
\hline Complete List of Authors: & $\begin{array}{l}\text { Davies, Theresa; University of Auckland, Surgery } \\
\text { Mudge, Suzie; AUT University, School of Rehabilitation and } \\
\text { Occupation Studies } \\
\text { Ameratunga, Shanthi; University of Aucland, School of Population } \\
\text { Health } \\
\text { Stott, Susan; University of Auckland, Surgery }\end{array}$ \\
\hline Keywords: & $\begin{array}{l}\text { cerebral palsy, assistive technology, computer access, self-directed, } \\
\text { assistive devices }\end{array}$ \\
\hline
\end{tabular}

\section{s ScholarONE" \\ Manuscript Central}


1

\section{Enabling self-directed computer use for individuals with cerebral palsy: a systematic review of available assistive devices and technologies.}

T. Claire Davies, BASc.(Hons), MSc., PhD, PEng.

Department of Surgery, University of Auckland

Suzie Mudge, Dip. Phys., MHSc., PhD, School of Rehabilitation and Occupation Studies, AUT University

Shanthi Ameratunga, MB ChB, PhD, FRACP (Paed)

Section of Epidemiology and Biostatistics, School of Population Health, University of Auckland

N. Susan Stott, MB ChB, PhD, FRACS

Department of Surgery, University of Auckland

Corresponding Author:

T. Claire Davies,

The University of Auckland,

Private Bag 92019

Auckland, 1142,

New Zealand

c.davies@auckland.ac.nz

Fax: 6493677159

Word Count: 4104 
Aim: The purpose of this study was to systematically review published evidence regarding the development, utilisation and effectiveness of devices and technologies that enable or enhance self-directed computer access by individuals with cerebral palsy.

Methods: Nine electronic databases and reference lists of included articles were searched using keywords computer, software, spastic, athetoid and cerebral palsy. Thirty articles were included of which 23 described development and usability testing of devices and seven evaluated modifications of existing algorithms to increase computer recognition of input and cursor movements.

Results: Twenty-four of the 30 studies had less than ten participants with CP, with a wide age range, 5 to 77 years. Computer task performance was usually tested but only three sought participant feedback on ease and comfort of use. International standards exist to evaluate effectiveness of non-keyboard devices, but only one undertook this testing. None of the studies were higher than AACPDM level IV evidence with respect to study design.

Interpretation: Access solutions for individuals with CP are in early developmental stages. Future work should include assessment of end-user comfort, effort and performance as well as design features. Engaging users and therapists when designing and evaluating technologies to enhance computer access may increase acceptance and improve performance.

Running foot: Computer access for individuals with CP 


\section{INTRODUCTION}

For many individuals, computer use is part of daily living. However, computers are largely designed for individuals with no physical or cognitive impairments ${ }^{(1)}$. A study by the US National Center for Education Statistics in 2003 showed that children with a disability between the ages of 5 and 17 are less likely to use computers or Internet than their counterparts ${ }^{(2,3)}$. From 2000 to 2003 , the numbers of children with disabilities accessing computers and the Internet have remained constant, but there has been an increase in access by children without disabilities ${ }^{(2,3)}$. For some disabled individuals, the barriers to computer use are external, such as limited income or absence of computers within the home environment. However, for others, physical impairments impair the ability to control devices in the immediate environment such as televisions, computers and other electronic equipment ${ }^{(4)}$.

Cerebral palsy (CP) is a common cause of motor dysfunction affecting children and adults ${ }^{(5)}$ and is an umbrella term for a group of disorders of movement and/or postures which include spasticity, dyskinesia, ataxia and hypotonia ${ }^{(6)}$. Until recently, it was believed that the prevalence of cerebral palsy had remained steady at 2 to 2.5 per 1000 live births ${ }^{(5)}$, but 2002 reports suggest that the prevalence is higher, more closely approximating 3.1 per 1,000 births ${ }^{(5)}$. Individuals with CP often experience barriers in the context of education, vocational training and communication with peers which leads to increasing societal isolation ${ }^{(7)}$. Independent and effective access to computers has the potential to address some of these barriers, particularly for those with multiple motor impairments ${ }^{(8)}$. However, little is known about the effectiveness with which individuals with $\mathrm{CP}$ with significant motor impairments access computers and what modifications are most useful in enabling access.

The purpose of this study was to systematically review published evidence regarding the development, utilisation and effectiveness of devices and technologies that enable or enhance self-directed computer access by individuals with cerebral palsy.

\section{METHODS}

\section{Search Strategy}

The literature search was limited to English language abstracts of articles published between January 1990 and August 4, 2009 in the following electronic databases: PubMed, Embase, ERIC (Education Resources Information Center), Engineering Village, Web of Science, Child Development and Adolescent Studies, DARE (Database of Abstracts of Reviews of Effectiveness), the Cochrane Database of Systematic Reviews, and PEDRO (the Physiotherapy Evidence Database). The electronic search terms used were ('computer' OR 'software') AND ('cerebral palsy' OR 'athetoid' OR 'spastic'). The two primary reviewers were a rehabilitation engineer with expertise in assistive technologies and a physical therapist with expertise in neurological rehabilitation. The third reviewer, a physician with expertise in the care of individuals with cerebral palsy, evaluated only the abstracts for which there was a disagreement between the two primary reviewers. All reviewers hold doctorates in their respective fields. After the initial search, the two primary reviewers independently assessed all abstracts for eligibility in the review based on the screening criteria (see below and Figure 1). The inter-reviewer reliability based on these initial reviews had a kappa value of 0.71 with a level of agreement of $98 \%$. Those abstracts that were considered as meeting the inclusion criteria by the two primary reviewers were automatically included in full review. Discrepancies between the two primary reviewers were resolved after abstract review by the third reviewer and through discussion among the three reviewers. If two reviewers determined that the inclusion criteria were not met, the abstract was rejected. Otherwise, if the abstract was considered by two reviewers to meet the inclusion criteria, then it was included in the review. The reference lists of the included papers were then also hand-searched for any additional studies and abstracts from these additional studies then reviewed. The same process of review by two primary reviewers, with resolution of discrepancies by input from with a third reviewer, was followed for assessment of the full papers for inclusion in the review, and for the levels of evidence and quality levels of the articles.

\section{Inclusion and Exclusion Criteria}


For the purpose of this review, the computer was defined as "a general-purpose computer equipped with a microprocessor and designed to run commercial software (such as a word processor or Internet browser) for an individual user" (9). All studies that reported on the testing of one or more assistive devices or technologies to enhance or facilitate computer use; and that included data from at least one individual with cerebral palsy were included. Studies that reported on devices or technology requiring caregiver input during the initial set-up of the device or computer were included. However, studies were excluded that focused on technologies that required the caregiver to be the 'proxy user' of the computer technology. As well, studies that focused on device technologies developed for orientation and mobility and the use of virtual reality for motor training or recreation were excluded. Only articles published in peer-reviewed journals or published as conference papers or abstracts were considered. Articles not published in English were also excluded.

\section{ORGANIZATION OF EVIDENCE}

The data extraction form used for this study was the critical review form for quantitative studies developed by the Occupational Therapy Evidence Based Practice Group at McMaster University ${ }^{(10)}$. This form allows the reviewer to summarise information about the study purpose, the background literature, the design of the study, the sample size, the outcome measures, interventions reported, results and conclusions. Two authors independently completed a critical review form for each study. The levels of evidence for the included studies were assessed by the AACPDM guidelines ${ }^{(11)}$.

\section{RESULTS}

Fig. 1 summarises the search results. Forty-eight abstracts appeared to meet the inclusion criteria and were obtained in full article format. Fifteen papers were excluded for the following reasons: no evidence of testing by individuals with $\mathrm{CP}^{(12-18)}$ and evaluation of training or assessment methods rather than technology ${ }^{(19-23)}$. A further two papers were excluded ${ }^{(24)}$ on the basis of either containing information that appeared identical to a previously published article by another author ${ }^{(25)}$, or reporting results from one patient that had also been summarized in another paper by the same author with additional participants ${ }^{(26)}$. A final study was excluded as the full article was not in English ${ }^{(27)}$. The same author had published similar work in English language journals that were included in the review ${ }^{(28-30)}$.

\section{Study Characteristics}

A total of thirty original papers, including 180 individuals with CP met the inclusion criteria for full review. Twenty-three of the 30 papers incorporated children and/or youth as defined by the WHO classification (3 years to 25 years) within their research. Only four studies reported on assessments of adults exclusively. The remaining three studies did not indicate the age of the participants. The functional levels of CP were not defined according to the GMFCS or MACS but most participants had what was described as spastic quadriplegia.

All studies were quantitative in nature. Study designs included: 11 case series, two before and after comparisons, five single case designs and 11 quasi-experimental designs ${ }^{(10)}$. One reported a variety of designs, but insufficient evidence was available to support this claim ${ }^{(31)}$. Case series involved task completion exercises with no mention of baseline comparison, whereas before and after designs looked at change in task performance from baseline. Single case designs used the participant as their own control, evaluating multiple different types of technology as compared to baseline to evaluate improved access (using intervention sequences such as ABAB, ABACA or ABCD). The quasi-experimental designs involved comparisons between small groups of individuals that were not matched (for example, athetoid $\mathrm{CP}$ versus spastic $\mathrm{CP})$.

\section{Outcome Measures:}

None of the studies included in this review classified outcomes in terms of the International Classification of Functioning (ICF) dimensions of health ${ }^{(32)}$. Most studies tested outcomes in terms of either impairment of body function (e.g. moving an on-screen cursor or using a keyboard) ${ }^{(25,31,33-50)}$ or in terms of theoretical mathematical changes in computer recognition of cursor input ${ }^{(26,28-30,51-55)}$. Only three studies sought 
feedback from participants about comfort and perceived ease of use ${ }^{(36,40,47)}$, with the study by Turpin et al. also seeking expert opinion from physiotherapists, occupational therapists, ergonomists and information technologists ${ }^{(40)}$.

Seven studies used typing and letter matching tasks to evaluate computer usability by determining the number of correct responses when transcribing information and the speed with which participants could match letters $(25,35,41-43,45,46)$. Another six examined the participant's time to respond through clicking and dragging tasks ${ }^{(33,36,38-40,44)}$. The amount of time to move to a target, the path distance as a function of target diameter and direction was determined and compared among devices, also known as Fitts' law. Fitts' law provides a relationship between the size of a target and the distance between targets and is an internationally validated method to test non-keyboard devices such as a mouse or joy-stick ${ }^{(36,51)}$. Seven studies reported on proficiency or ability to physically access the computer through successful task performances ${ }^{(34,37,47-50,56)}$ including correct identification of yes/no recognition by the computer as compared to two trained observers ${ }^{(49)}$ and rate of information transfer in bits per trial ${ }^{(50)}$. One study reported using all three of these methods, though the results were not reported ${ }^{(31)}$.

Nine studies used theoretical modelling to assess improvements in computer recognition of mouse movements etc but did not test in real-time. These modelled ideal cursor responses based on initial tests with individuals with cerebral palsy, but did not further test to evaluate effectiveness of the model ${ }^{(26,28-30,51-}$ 55)

\section{Methodological Quality:}

The level of evidence was based on the AACPDM guidelines ${ }^{(57)}$. None of the studies included in the review were higher than level IV evidence with respect to study design.

Only one study followed the International Standards Organization (ISO 9241-9, the international standard for "Ergonomic Requirements for Office Work with Visual Display Terminals (VDTs) Part 9", 2000) guidelines for assessing performance, comfort and effort to ensure minimal cognitive load through the Fitts' task analyses with efficiency in motor control ${ }^{(36)}$. Three did include analyses of movement time to evaluate performance ${ }^{(38,51,52)}$, but only the study by Havstam et al. ${ }^{(47)}$ also sought input about perceived comfort. Expert feedback was sought by only one study ${ }^{(40)}$.

\section{Research Results:}

The research studies could be grouped into two general areas. These were based on the type of participation of the individuals with cerebral palsy. If the participants were involved in the design stages or performed tests to evaluate final performance of the device, they were grouped together. The other category used a set of historical data previously collected by the researchers to work on algorithms to improve computer recognition of the response. The end-user was not involved in any subsequent testing.

(a) Development and Usability Testing:

Table S1 (supplementary information published online) provides an overview of the results of the 23 studies that describe the development and usability testing of customised devices. Although several of these papers also include results from participants who did not have $\mathrm{CP}$, only the results from those with $\mathrm{CP}$ are reported, unless otherwise indicated.

\section{Pointing Devices:}

These were evaluated in ten studies ${ }^{(25,33-40)}$. Two used single case designs allowing comparison to baseline measures ${ }^{(35,36)}$. Durfee and Billingsley evaluated a touch screen compared to an onscreen enlarged arrow and found the arrow to be better than the touch screen which the participant had used for two years ${ }^{(35)}$. Man and Wong found that a Cross Scanner was rated highest for comfort by participants yet an ASL mouse emulator showed better performance ${ }^{(36)}$. Rao et al. presented a study of joystick control requiring each subject to participate in testing over two sessions per day for two days ${ }^{(38)}$. Each session included trials with four target sizes, three repetitions and two directions of movement. The results showed lower movement time and path distance with a position joystick as compared to an isometric joystick with a greater difference between the two becoming more evident with increasing severity of CP. 


\section{Keyboard Modifications:}

Generally, speed and accuracy improved with the use of keyboard modifications. Lin et al. ${ }^{(41)}$ found that a chorded onscreen keyboard was faster and more accurate than a keyboard and mouse for a single study participant. McCormack ${ }^{(58)}$ found that use of a customised keyguard to minimise unwanted key depression increased accuracy of input, but decreased the speed of typing, creating a speed-accuracy trade-off. The most comprehensive study of keyboard modifications ${ }^{(43)}$, suggested that currently available accessibility options within the Windows environment (sticky keys, key repeat, post-acceptance delay) can enable both increased speed and accuracy of typing when compared to a standard keyboard. This study was level IV evidence.

\section{Screen Interface Options:}

One of the accessibility options available within the Windows environment is the ability to scan through screen icons. The cursor systematically moves across the icons in a chosen mode, such as automatic (clicking a switch), inverse (holding switch down and releasing) and step scanning (successive clicking). Automatic scanning was shown to be difficult for individuals with spastic CP and step scanning was poor for those with athetoid $\mathrm{CP}{ }^{(44)}$. However, results were inconclusive regarding the best method for each group. Efficiency improved without affecting the accuracy with the use of an input device agent (IDA) to select a scanning speed as opposed to self selection ${ }^{(45)}$.

Two studies used computational modelling to provide indicators about the ideal number and size of targets on the screen ${ }^{(51,52)}$. Models were developed to estimate the size of target that allowed most efficient response by a specific user. The results from these models suggest that often when the therapist uses trial and error to select graphic (target) size, the targets are smaller than ideal for the user, but the final model was not tested with users.

Symbols representing whole words or phrases can provide a method for non-verbal children to communicate when linked to a voice output communication device. Children with significant physical impairments who are unable to point, use visual scanning and switches to select symbols. Symbol prediction software is a method of access which involves highlighting a specific symbol within an array based on an expected, or predicted, response ${ }^{(46)}$. Highlighting predicted symbols within an array was found to decrease participant response time to find the symbol compared to no predictive response (requiring the participant to search for the symbol within an array). However, there was a trade-off between speed and accuracy with participants more likely to make errors in symbol selection with a predicted array ${ }^{(46)}$.

\section{Speech and Gesture Recognition Software:}

Speech recognition software is difficult to customise for users with cerebral palsy who have dysarthric speech. Two studies involved the use of utterances or verbal commads to dictate information to a computer to enable access ${ }^{(47,48)}$. A combination of feedback information through auditory repeat (to enable the user to hear the utterance) and visual feedback (supplied by a bar chart of successful recognition) may help users to reduce variability in dysarthric utterances and enable increased recognition by speech recognition software, but this training requires significant time and dedication. Gesture recognition also requires training of the software by repeating actions (hand or head movements) many times until the software can interpret the action $^{(49,54)}$. The NAVIGO software is a solution that allows for a variety of different input types and interfaces as well as allowing for incremental changes as the user's ability to use a computer improves ${ }^{(56)}$. One study evaluated its ease of customisation in three participants and suggested that the software is easy to adapt ${ }^{(56)}$. A final study investigated brain computer interfacing, which capitalises on EEG signals but found successful use of this technology very dependent on the user ${ }^{(50)}$.

(b) Improvements to filtering mechanisms to improve recognition of keyboard typing or cursor movement:

Seven papers used data previously collected from individuals with cerebral palsy to develop and test theoretical filtering mechanisms or algorithms that could improve accuracy of computer - recognition of keyboard input or tracking of cursor movement (Table S2, supplementary information published online). A response in this situation was defined as improved recognition by the computer software of either inputs 
from switches ${ }^{(28-30,53,55)}$ or cursor movement ${ }^{(26,54)}$. Subsequent testing of the proposed filtering mechanisms or new post-processing algorithms with new participants was not reported.

For those individuals who cannot access a keyboard, switches can be used for Morse code signals. The high variability in signal length (dots and dashes) switched by an individual with cerebral palsy led Luo, in the $1990 \mathrm{~s}$, to investigate improvements to the algorithm that would allow these signals to be correctly identified $^{(59,60)}$. Luo has continued this research with a variety of collaborators to improve the signal detection accuracy ${ }^{(27,28,30,53,55)}$. All the raw data were collected by asking individuals to input a message using Morse code which is then processed and filtered, but the improved algorithm has not been tested either in real time or with other participants.

The final two studies in this group addressed computer recognition of cursor movement and sought to decrease the time to click on a target and improve target prediction by refinement of computer software algorithms for those individuals with athetoid movement of the upper extremity who have difficulty controlling the hand while also clicking on an icon. Mathematical analyses showed that additional model and filters within the computer software could theoretically improve icon selection when using a mouse as the input, but this was not tested in real time with participants ${ }^{(26)}$.

\section{DISCUSSION}

The goal of this systematic review was to identify research describing the development and testing of assistive devices to enable self-directed computer access by individuals with cerebral palsy. In total, 30 studies were found that investigated aspects of computer accessibility to individuals with cerebral palsy. Although individuals with cerebral palsy make up a very heterogeneous group, the majority of the studies identified in this review did not describe the characteristics of the population studied in any detail or discuss the needs / goals of the individual study participants. None of these papers met good experimental design procedures as determined by AACPDM levels of evidence ${ }^{(11)}$ and only one followed ISO guidelines for testing non-keyboard access devices.

Most of the studies (all in Table S1) reported on physical access to the computer i.e. devices or technologies that make it easier to manoeuvre the cursor on the screen to a specific icon such as modified mouse, joystick or speech and gesture recognition software. There was some evidence based on results of 20 children (2 studies) with cerebral palsy to suggest that a joystick, more specifically a position joystick, may provide better control than a standard mouse or trackball ${ }^{(38,39)}$. However, in one case, use of a standard mouse with an enlarged cursor size on the screen was found to be more effective than the use of a touch screen, even though the participant had used a touch screen for several years ${ }^{(35)}$. This suggests that the use of Accessibility Options already present within the Windows environment should be considered before looking to different assistive technologies to enhance pointing ability. While speech recognition, gesture recognition and brain computer interfacing were reported by some authors as alternative ways to enable physical computer access, the amount of time required to train individuals to use these systems requires significant motivation and stamina by both the individual and the therapist ${ }^{(48-50)}$. Unless these modalities can be honed to enable more easily learnt responses, they are unlikely to come into mainstream practice.

From this review, most of the available technology is still at an early phase of development. There have not been any comprehensive large scale intervention studies of assistive technologies and most researchers are using a single case study design. Given the individualised modifications or innovations required, some argue that single case studies may be the only method to analyse success for individuals with cerebral palsy ${ }^{(44)}$. However, universal design, i.e. design that enables access by individuals with a wide range of abilities, has been identified as a priority by the World Health Organisation and is one way to reduce the experience of disability ${ }^{(61)}$. Yeh et al. present a first attempt at bridging the digital divide with a cross-disciplinary usercentred design approach to evaluation, testing and prescribing assistive technology. NAVIGO software allows for different input and output devices as well as variable cursor control and size ${ }^{(56)}$. These solutions are particularly encouraging but need further testing.

There is also a need for a systematic evaluation approach with consideration of efficiency, performance, comfort and effort. Although international standards exist to evaluate the performance, comfort and effort of computer pointing devices (ISO 9241-9), only one study used these standards ${ }^{(36)}$. Three others used the 
Fitts law task as a measure of performance ${ }^{(38,51,52)}$, but did not include input from the users about comfort and effort. Adopting criteria such as the ISO universal access guidelines would improve both the consistency of results and facilitate comparison of access solutions. Furthermore, user models resulting from the ISO standards might enable more efficient prescription of graphic size and target number ${ }^{(51,52)}$. Larger, more controlled studies are needed to enable therapists to provide individualised guidance to their clients based on sound evidence.

Of concern is the apparent gap between researchers in the area of assistive technology device and the endusers, including therapists, educators, employers and individuals with cerebral palsy. Studies described the technology in detail but lacked descriptions of the match between the technology and the needs of the user. As well, within most studies, participants were passive subjects, involved in aspects of validation of the device, but not actively involved in either the initial design phase or the post-hoc analysis. Two studies reported that individuals chose not to complete the study ${ }^{(47,48)}$. Lack of motivation was cited as the reason. However, it may have been that the researchers failed to effectively engage the individual participants in the goals of the research. Many research groups are working to design devices that they hope will benefit the population of individuals with cerebral palsy. However, their design methods do not appear to involve usercentred design or focus groups within the population or their caregivers. Designing with a multi-disciplinary approach can lead to increased acceptance of devices; increased use and improved performance ${ }^{(31,62,63)}$. Careful evaluation of the needs of the user and selection of a device that is easy to use with maximum comfort is likely to be as important as target performance ${ }^{(36)}$.

\section{LIMITATIONS OF THIS REVIEW}

An attempt was made to ensure that all literature pertaining to access of computers by individuals with cerebral palsy was reviewed. However, other research may exist in which cerebral palsy, athetoid or spastic was not identified as a key term within the article. For instance, engineering articles that discuss the development of devices often do not discuss the target population in detail. Every effort was made to crossreference with other articles drawn from the references of the selected articles. Only articles after 1990 were included as computer access was limited prior to this timeframe. This review did include published conference papers / abstracts as well as full peer-reviewed papers but did not include abstracts written in languages other than English or unpublished data. Some studies may have therefore been excluded on this basis leading to potential bias. Only one full non-English article was excluded; as that author had also published several similar papers in English

\section{CONCLUSIONS}

A range of accessibility solutions are available for the individual with cerebral palsy to access a computer, but few have undergone rigorous experimental testing and there is little evidence to suggest that one or more of these devices could enable access for a specific individual. Pointing devices and keyboard modifications may enable access for some, but the results of these studies cannot be applied to the population of cerebral palsy users as a whole. There is a need for systematic and comprehensive approaches to evaluating devices including the assessment of end-user comfort and effort, in addition to performance. Adopting criteria such as the ISO universal access guidelines would improve both the consistency of results and facilitate comparison of access solutions. Larger, more comprehensive studies that group results based on participant functional ability, and that consider both environmental factors and personal factors, must be undertaken in future studies of technology effectiveness. Overall, greater methodological rigor is required to obtain stronger empirical evidence of the efficacy and effectiveness of technologies for self-directed computer access by individuals with CP. Finally, engaging users and therapists when designing and evaluating technologies to enhance computer access is likely to increase acceptance, improve performance and enable the goal of universal access. 
References

1. Department of Commerce. Falling through the Net? A Digital Divide Still Exists for Some Americans. [Washington, D.C.] :; 2000.

2. DeBell M, Chapman C, Statistics. NCfE. Computer and internet use by children and adolescents in 2001 [electronic resource] / Matthew Debell, Chris Chapman. [Washington, D.C.] :; 2003.

3. DeBell M, Chapman C. Computer and internet use by children and adolescents in 2003 [electronic resource] 2006- N, 065). editors. [Washington, D.C.] :: U.S. Department of Education. Washington, DC: National Center for Education Statistics.; 2006.

4. Craig A, Tran Y, Mclsaac P, Boord P. The efficacy and benefits of environmental control systems for the severely disabled. Med Sci Monit. 2005 Jan;11(1):RA32-9.

5. Yeargin-Allsopp M, Van Naarden Braun K, Doernberg NS, Benedict RE, Kirby RS, Durkin MS. Prevalence of cerebral palsy in 8-year-old children in three areas of the United States in 2002: a multisite collaboration. Pediatrics. 2008 Mar;121(3):547-54.

6. Access Economics Pty Limited. The economic impact of cerebral palsy in Australia in 2007. April, 2008.

7. Liptak GS, Accardo PJ. Health and social outcomes of children with cerebral palsy. J Pediatr. 2004 Aug;145(2 Suppl):S36-

41.

8. Hoppestad BS. Inadequacies in computer access using assistive technology devices in profoundly disabled individuals: an overview of the current literature. Disabil Rehabil Assist Technol. 2007 Jul;2(4):189-99.

9. Miriam-Webster Dictionary Online. 2009 [updated 2009; cited Janury 9, 2009]; Available from: http://www.merriamwebster.com/dictionary/personal\%20computer.

10. Law M, Stwear, D., Pollock, N., Letts, L., Bosch, J., and Westmorland, M., . Critical Review Form - Quantitative Studies. Hamilton: University of McMaster; 1998 [updated 1998; cited December, 2008

]; Available from: http://www.srs-mcmaster.ca/Default.aspx?tabid=630.

11. Darrah JH, R; O'Donell, M; Vogtle, L; Wiart, L., . AACPDM Methodology to develop systematic reviews of treatment interventions. Revision 1.2. In: Committee TO, editor.: AACPDM; 2008.

12. Lin ML, Radwin RG, Vanderheiden GC. Gain effects on performance using a head-controlled computer input device. Ergonomics. [Article]. 1992 Feb;35(2):159-75.

13. Harrington ME, Daniel RW, Kyberd PJ. A measurement system for the recognition of arm gestures using accelerometers. Proc Inst Mech Eng [H]. 1995;209(2):129-34.

14. Blaney B, Wilson J. Acoustic variability in dysarthria and computer speech recognition. Clin Linguist Phon. [Article]. 2000 Jun;14(4):307-27.

15. Deller JR, Jr., Snider RK, editors. 'Quantized' hidden Markov models for efficient recognition of cerebral palsy speech; 1990; Piscataway, NJ, USA. Publ by IEEE.

16. LaCourse JR, Hludik FC, Jr. An eye movement communication-control system for the disabled. IEEE Trans Biomed Eng. 1990;37(12):1215-20.

17. Wobbrock JO, Myers BA, Hudson SE, editors. Exploring edge-based input techniques for handheld text entry. 23rd International Conference on Distributed Computing Systems Workshops; 2003 May 19-22; Providence, Ri. leee Computer Soc. 18. Mauri C, Granollers T, Solanas A, editors. On the assessment of the interaction quality of users with cerebral palsy; 2007; Piscataway, NJ 08855-1331, United States. Institute of Electrical and Electronics Engineers Computer Society.

19. Meng LF, Li TY, Chu CN, Chen MC, Chang SCH, Chou AM, et al., editors. Applications of computer access approach to persons with quadriplegics. 9th International Conference on Computers Helping People with Special Needs; 2004 Jul 07-09; Paris, FRANCE. Springer-Verlag Berlin.

20. Kwee H, Quaedackers J, Van De Bool E, Theeuwen L, Speth L. Adapting the control of the MANUS manipulator for persons with cerebral palsy: An exploratory study. Technology and Disability. 2002;14(1):31-42.

21. Hird K, Hennessey NW. Facilitating use of speech recognition software for people with disabilities: a comparison of three treatments. Clin Linguist Phon. 2007;21(3):211-26.

22. Mazer BDCVC. Validation of the assessment of computer task performance for children. Technology and Disability. 2003;15(1):35-43.

23. Angelo J, Buning ME, Schmeler M, Doster S. Identifying best practice in the occupational therapy assistive technology evaluation: an analysis of three focus groups. Am J Occup Ther. 1997 Nov-Dec;51(10):916-20.

24. Atyabi M, Hosseini MSK, Mokhtari M, leee, editors. The Webcam Mouse: Visual 3D tracking of body features to provide computer access for people with severe disabilities. Annual IEEE India Conference; 2006 Sep 15; New Delhi, INDIA. Ieee.

25. Betke M, Gips J, Fleming P. The camera mouse: visual tracking of body features to provide computer access for people with severe disabilities. IEEE Trans Neural Syst Rehabil Eng. 2002;10(1):1-10.

26. Olds KC, Sibenaller S, Cooper RA, Ding D, Riviere C, editors. Target prediction for icon clicking by athetoid persons; 2008; Piscataway, NJ 08855-1331, United States. Institute of Electrical and Electronics Engineers Inc.

27. Yang $\mathrm{CH}$. A new Mandarin phonetic morse code recognition method using a variant LMS algorithm. J Chin Inst Eng.

[Article]. 2000 Nov;23(6):741-8.

28. Yang $\mathrm{CH}$. Adaptive Morse code recognition using variable degree variable step size LMS for persons with disabilities.

Biomed Mater Eng. 1998;8(5-6):343-52.

29. Yang $\mathrm{CH}$, Jin LC, Chuang LY. Fuzzy support vector machines for adaptive Morse code recognition. Med Eng Phys. 2006;28(9):925-31. 
30. Yang $\mathrm{CH}$, Luo $\mathrm{CH}$, Chuang LY. Counter-propagation network with variable degree variable step size LMS for single switch typing recognition. Biomed Mater Eng. 2004;14(1):23-32.

31. Yeh YM, Wu TF, Meng LF, Chen MC, Wang HP, Wu JG, et al. Characteristics and solutions of digital divide for people with physical impairments in Taiwan. Computers Helping People with Special Needs, Proceedings. 2008;5105:1332-9

50.

32. World Health Organization. International classification of functioning, disability and health. Geneva; 2001 Contract No.: Document Number|.

33. Chen CL, Wu CY, Chen HC, Hong WH, Liu WY, Wong AMK, et al. Application of a novel integrated pointing device apparatus for children with cerebral palsy. Chang Gung Medical Journal. 2006 Jul;29(4):380-7.

34. Clayton CJ. An intra-oral access device. J Med Eng Technol. 1992;16(5):204-9.

35. Durfee JL, Billingsley FF. A comparison of two computer input devices for uppercase letter matching. Am J Occup Ther. 1999;53(2):214-20.

36. Man DWK, Wong MSL. Evaluation of computer-access solutions for students with quadriplegic athetoid cerebral palsy. Am J Occup Ther. [Article]. 2007 May-Jun;61(3):355-64.

37. Mukherjee A, Chakraborty K, Basu A. SweepSticks: an adaptive virtual mouse for people with neuromotor disorders. Assist Technol. 2008;20(2):111-24.

38. Rao RS, Seliktar R, Rahman T. Evaluation of an isometric and a position joystick in a target acquisition task for individuals with cerebral palsy. IEEE Trans Rehabil Eng. 2000;8(1):118-25.

39. Wu TF, Chen MC, editors. Performance of different pointing devices on children with cerebral palsy. 4th International Conference on Universal Access in Human-Computer Interaction held at the HCl International 2007; 2007 Jul 22-27; Beijing, Peoples Republic of China. Springer-Verlag Berlin.

40. Turpin G, Armstrong J, Frost P, Fine B, Ward C, Pinnington L. Evaluation of alternative computer input devices used by people with disabilities. J Med Eng Technol. 2005 May-Jun;29(3):119-29.

41. Lin YL, Chen MC, Yeh CC, Yeh YM, Wang HP, editors. Assisting an adolescent with cerebral palsy to entry text by using the chorded keyboard. 11th International Conference on Computers Helping People with Special Needs; 2008 Jul 09-11; Linz, AUSTRIA. Springer-Verlag Berlin.

42. McCormack DJ. The effects of keyguard use and pelvic positioning on typing speed and accuracy in a boy with cerebral palsy. Am J Occup Ther. 1990;44(4):312-5.

43. Wu T-F, Chen M-C, editors. Keyboard adaptations for children with cerebral palsy; 2006; Heidelberg, D-69121, Germany. Springer Verlag.

44. Angelo J. Comparison of three computer scanning modes as an interface method for persons with cerebral palsy. Am J Occup Ther. 1992;46(3):217-22.

45. Simpson R, Koester H, LoPresti E. Evaluation of an adaptive row/column scanning system. Technology and Disability. 2006;18(3):127-38.

46. Stewart $\mathrm{H}$, Wilcock $\mathrm{A}$. Improving the communication rate for symbol based, scanning voice output device users. Technology and Disability. 2001;13(3):141-50.

47. Havstam C, Buchholz M, Hartelius L. Speech recognition and dysarthria: a single subject study of two individuals with profound impairment of speech and motor control. Logoped Phoniatr Vocol. 2003;28(2):81-90.

48. Parker M, Cunningham S, Enderby P, Hawley M, Green P. Automatic speech recognition and training for severely dysarthric users of assistive technology: the STARDUST project. Clin Linguist Phon. 2006;20(2-3):149-56.

49. Harwin WS, Jackson RD. Analysis of intentional head gestures to assist computer access by physically disabled people. J Biomed Eng. 1990;12(3):193-8.

50. McFarland DJ, Sarnacki WA, Wolpaw JR. Brain-computer interface (BCI) operation: optimizing information transfer rates. Biol Psychol. 2003;63(3):237-51.

51. Radwin RG, Vanderheiden GC, Lin ML. A method for evaluating head-controlled computer input devices using Fitts' law. Hum Factors. 1990;32(4):423-38.

52. Sanger TD, Henderson J. Optimizing assisted communication devices for Children with motor impairments using a model of information rate and channel capacity. IEEE Trans Neural Syst Rehabil Eng. 2007;15(3):458-68.

53. Fuh DT, Luo CH. Unstable Morse Code recognition system with back propagation neural network for person with disabilities. J Med Eng Technol. 2001;25(3):118-23.

54. Morrison K, McKenna SJ. Automatic visual recognition of gestures made by motor-impaired computer users.

Technology and Disability. 2002;14(4):197-203.

55. Wu CM, Luo $\mathrm{CH}$. Morse code recognition system with fuzzy algorithm for disabled persons. J Med Eng Technol. 2002;26(5):202-7.

56. Pokhariya H, Kulkarni P, Kantroo V, Jindal T, editors. Navigo - Accessibility solutions for cerebral palsy affected; 2007; Piscataway, NJ 08855-1331, United States. Institute of Electrical and Electronics Engineers Computer Society.

57. Butler C. AACPDM Methodology to develop systematic reviews of treatment interventions. In: Committee TO, editor.: AACPDM; 1999.

58. McCormack DJ. The effects of keyguard use and pelvic positioning on typing speed and accuracy in a boy with cerebral palsy. Am J Occup Ther. 1990 Apr;44(4):312-5.

59. Luo $\mathrm{C}-\mathrm{H}$, Shih $\mathrm{C}-\mathrm{H}$. Adaptive Morse-coded single-switch communication system for the disabled. International Journal of Biomedical Computing. 1996;41(2):99-106. 
60. Shih C-H, Luo C-H. Morse-code recognition system with LMS and matching algorithms for persons with disabilities. International Journal of Medical Informatics. 1997;44(3):193-202.

61. World Health Organization. Towards a common language for functioning, disability and health. Geneva; 2002.

62. Weightman APH, Preston N, Holt R, Allsop M, Levesley M, Bhakta B. Engaging children in healthcare technology design: developing rehabilitation technology for children with cerebral palsy. Journal of Engineering Design. 2008.

63. Rigby P, Ryan S, From W, Walczak E, Jutai J. A client-centred approach to developing assistive technology with children. Occupational Therapy International. 1996;3(1):67-79. 
Figure 1: Flow diagram of selected studies for final review.

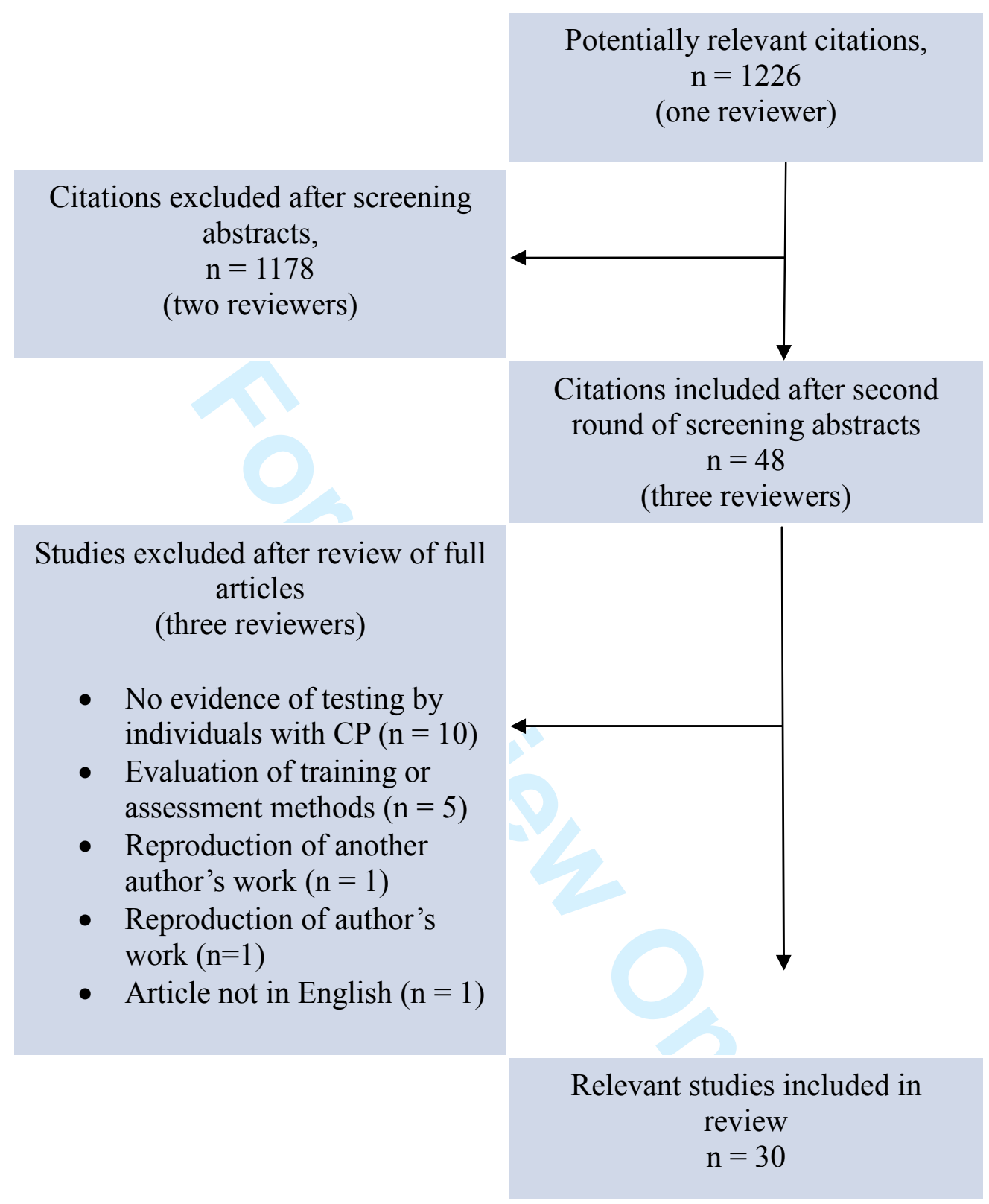


Table S1: Development and Usability Testing of Customised Devices to Enable/Enhance Computer Use

\begin{tabular}{|c|c|c|c|c|c|c|}
\hline Author, year & $\begin{array}{l}\text { Research } \\
\text { Design/ }\end{array}$ & Participants & $\begin{array}{l}\text { Total } n \text { (oth=other, } \\
\text { cntl = control) }\end{array}$ & $\begin{array}{l}\text { Age }(s) \text {, } \\
\text { years } \\
(C P)\end{array}$ & Device/technique & Measures \\
\hline
\end{tabular}

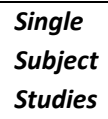

$1 \mathrm{CP}=1$

23 Computer

recognition of head gestures

spastic quadriplegia $\quad 1 \mathrm{CP}=1$

Durfee,

IV - single case design $A B A B$ $\mathrm{CP}$ with impaired vision and cognitive level of 3 or 4 yrs

5
5
5
6
7
8
9
6

athetoid
quadriplegic, 2
athetoid/spastic
quadriplegic
non-speaking,
limited voluntary
muscle control
$3, \mathrm{CP}=3$
6-10
12, $\mathrm{CP}=10$, oth $=2(\mathrm{~TB}) \quad 3-58$

Internal symbol prediction, regular prediction, no prediction

Camera Mouse:

Visual tracking of gestures

Speed \&
accuracy of
typing

Use of keyguard increased accuracy $(p<0.01)$ and decreased speed $(p<0.01)$

Learning rate $\quad L R$ for one participant (LR), Movement with CP was better than time (MT), all other participants. For Total Path that participant, the Distance (PD) as function of Target Diameter (TD), cursor-target distance (CTD), and Direction

(D)

proficiency, use

Improved proficiency and use with newer intraoral access device (less inadvertant activation of sensors by swallowing).Compact size of mouthplate makes it unobtrusive.

Yes/No

recognition over one hour

Two independent observers and the computer identified yes/no gestures. $74 \%$ of time the 2 observers and the computer were in agreement.

Median accuracy ABAB; $43 \%, 53 \%, 55 \%, 68 \%$ respectively; also $14 \%$ less variability during $B$ periods.

$\begin{array}{ll}\begin{array}{l}\text { time to } \\ \text { complete } \\ \text { sentence, } \\ \text { errors }\end{array} & \begin{array}{l}\text { Overall, internal } \\ \text { prediction faster than no } \\ \text { prediction, but fewer } \\ \text { errors with no prediction }\end{array} \\ \begin{array}{l}\text { use Camera } \\ \text { Mouse } \\ \text { spell with } \\ \text { onscreen KB }\end{array} & \begin{array}{l}8 / 10 \text { able to use Camera } \\ \text { Mouse, } 5 / 10 \text { able to }\end{array} \\ \end{array}$


Author, year Research Participants

Total $n$ (oth=other,

Age(s), Device/technique

Measures

Outcome

Design/

cntl = control)

years

(CP)

\begin{tabular}{|c|c|c|c|c|c|c|c|}
\hline $\begin{array}{l}\text { McFarland, } \\
2003^{(50)}\end{array}$ & $\begin{array}{l}\text { IV - quasi- } \\
\text { experimental }\end{array}$ & CP (wheelchair) & $\begin{array}{l}8, \mathrm{CP}=1, \mathrm{cnt}=6, \text { oth }=1 \\
\text { ( } \mathrm{SCl}-\text { spinal cord } \\
\text { injury) }\end{array}$ & $\begin{array}{l}* 20- \\
44\end{array}$ & $\begin{array}{l}\text { Brain computer } \\
\text { interface }\end{array}$ & $\begin{array}{l}\text { Accuracy and } \\
\text { rate of } \\
\text { information } \\
\text { transfer } \\
\text { through EEG }\end{array}$ & $\begin{array}{l}\text { * Accuracy decreased for } \\
\text { increased number of } \\
\text { targets ( } p<0.0001) \text {, bits } \\
\text { per trial was highest for } \\
4 \text { targets ( } p<0.0003 \text { ). } \\
\text { Strong user effect on } \\
\text { accuracy and bits/trial } \\
(p<0.0001) .\end{array}$ \\
\hline
\end{tabular}

\begin{tabular}{|c|c|c|c|c|c|c|c|}
\hline $\begin{array}{l}\text { Havstam, } \\
2003^{(47)}\end{array}$ & $\begin{array}{l}\text { IV - single } \\
\text { case design } \\
\text { ABA }\end{array}$ & $\begin{array}{l}\text { spastic } \\
\text { quadriparesis }\end{array}$ & $2, C P=2$ & 12,22 & $\begin{array}{l}\text { Dragon Dictate - } \\
\text { speech recognition } \\
\text { software }\end{array}$ & $\begin{array}{l}\text { Computer } \\
\text { access system } \\
\text { efficiency, } \\
\text { perceived } \\
\text { peformance \& } \\
\text { comfort } \\
\text { level of success } \\
\text { in speech } \\
\text { recognition } \\
\text { speech } \\
\text { production }\end{array}$ & $\begin{array}{l}\text { One participant lost } \\
\text { motivation and training } \\
\text { was abandoned. Other } \\
\text { participant improved on } \\
\text { all measures during } \\
\text { treatment phase ( } 40 \% \\
\text { improvement in speech } \\
\text { recognition rate), except } \\
\text { speech production. }\end{array}$ \\
\hline
\end{tabular}

\begin{tabular}{|c|c|c|c|c|c|c|c|}
\hline $\begin{array}{l}\text { Turpin, } \\
2005^{(40)}\end{array}$ & $\begin{array}{l}\text { V - quasi- } \\
\text { experimental }\end{array}$ & $\mathrm{CP}$ & $\begin{array}{l}35, \mathrm{CP}=1 \text {, oth=34 }(11 \\
\text { - rheumatological } \\
\text { conditions, } 8 \text { - } \\
\text { musculoskeletal } \\
\text { conditions, } 15 \text { - other } \\
\text { conditions affecting } \\
\text { computer access) }\end{array}$ & $\begin{array}{l}* 32- \\
77\end{array}$ & $\begin{array}{l}\text { KB: compact, } \\
\text { expanded, } \\
\text { keyguard } \\
\text { PD: trackballs, } \\
\text { joystick-shaped } \\
\text { mouse, touchpad, } \\
\text { adjustable mouse, } \\
\text { wireless infrared } \\
\text { head pointer }\end{array}$ & $\begin{array}{l}\text { opening/closing } \\
\text { files, typing } \\
\text { sentence, } \\
\text { selecting text, } \\
\text { cutting, pasting } \\
\text { \& moving text, } \\
\text { scrolling }\end{array}$ & $\begin{array}{l}\text { Study presents matrices } \\
\text { of product features and } \\
\text { user impairments }\end{array}$ \\
\hline $\begin{array}{l}\text { Man, } \\
2007^{(36)}\end{array}$ & $\begin{array}{l}\text { IV - single } \\
\text { case design } \\
A B C D\end{array}$ & $\begin{array}{l}\text { no voluntary } \\
\text { control of four } \\
\text { limbs, average } \\
\text { intelligence }\end{array}$ & $2, C P=2$ & 13,15 & $\begin{array}{l}\text { Camera Mouse (A), } \\
\text { ASL Head Array } \\
\text { Mouse Emulator } \\
\text { (B), Cross Scanner } \\
\text { (C), Quick Glance } \\
\text { Eye Tracking } \\
\text { System (D) }\end{array}$ & $\begin{array}{l}\text { Winfitts (mean } \\
\text { movement } \\
\text { time, mean } \\
\text { accuracy rate) } \\
\text { Assessment of } \\
\text { Comfort } \\
\text { Questionnaire } \\
\text { (comfort) }\end{array}$ & $\begin{array}{l}\text { ASL Mouse Emulator had } \\
\text { lowest mean movement } \\
\text { time for both } \\
\text { participants ( } 12.5 \pm 5.63 \mathrm{~s} \text {, } \\
11.9 \pm 1.39 \mathrm{~s}) . \text { The Cross } \\
\text { Scanner had the highest } \\
\text { rate of accuracy for both } \\
(95.9 \pm 11.7 \% \text {, } \\
98.6 \pm 3.8 \%) . \text { The Cross } \\
\text { Scanner was rated } \\
\text { highest for level of } \\
\text { comfort by both } \\
\text { participants. }\end{array}$ \\
\hline $\begin{array}{l}\text { Pokhariya, } \\
2007^{(56)}\end{array}$ & $\begin{array}{l}\text { V - case } \\
\text { studies }\end{array}$ & $\begin{array}{l}1 \mathrm{CP} \text { severe } \\
\text { dysarthria and } \\
\text { quadriplegia } 1 \mathrm{CP} \\
\text { average user }\end{array}$ & $3, C P=3$ & NS & $\begin{array}{l}\text { NAVIGO - easily } \\
\text { modified universal } \\
\text { access solution }\end{array}$ & use & $\begin{array}{l}\text { Determined number of } \\
\text { sounds, controls, } \\
\text { alphabet letters, } \\
\text { tryboard areas, gestures, } \\
\text { and numbers that could } \\
\text { be used to customize } \\
\text { system for each } \\
\text { participant }\end{array}$ \\
\hline
\end{tabular}


Author, year Research Participants Design/

Total $n$ (oth=other,

Age(s),

Device/technique

Measures

Outcome

6
7
8
9
0
1
2
3
4
5
6
7
8
9
0
1
5
5
5
5
6
57
5
5

$\begin{array}{lll}\text { Sanger, } & \text { IV - quasi- } & \text { static upper } \\ 2007^{(52)} & \text { experimental } & \text { extremity, } \\ & & \text { Melbourne }=34 \% \\ & & \text { to } 77 \%\end{array}$

\section{Lin, $2008^{(41)} \quad V$ - case study athetoid}

Mukherjee, V-case

$2008^{(37) \quad \text { studies }}$

Group Studies

3 spastic, 3

athetoid

group

comparison

Rao, $2000^{(38)}$

IV - quasi- mild, moderate, experimental severe CP

$\begin{array}{lll}30, \mathrm{CP}=10, \mathrm{cnt} l=20 & 7-18 & \begin{array}{l}\text { Keyboard layout } \\ \text { prediction }\end{array}\end{array}$

Information
rate (measured
$\&$ predicted)

based on

movement

time and

reaction time

to size,

sequence and

number of

targets.

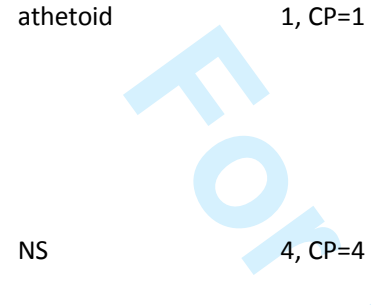

$\begin{array}{lll}\text { Chen, } & \text { IV - quasi- } & \text { severe spastic CP } \\ 2006^{(33)} & \text { experimental } & \text { with quadriplegia } \\ & \text { or athetoid CP } \\ & \text { with quadriplegia, } \\ & \text { good vision after } \\ & \text { visual correction } \\ & \text { and no active } \\ & \text { infection such as } \\ & \text { pneumonia }\end{array}$
keyboard vs performance: keyboard \& mouse speed \& accuracy

successful task performance mouse with and without predictive actions

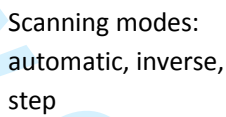
step

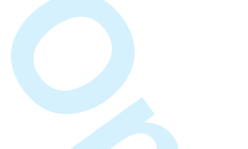

Isometric joystick vs spring-centred position joystick

\section{Movement time (MT), Total Path Distance (PD) as function of Target Diameter (TD), cursor-target distance (CTD), and Direction} (D)

\begin{tabular}{|c|c|c|c|}
\hline $42, \mathrm{CP}=27, \mathrm{cntl}=15$ & $5-12$ & $\begin{array}{l}\text { Integrated Pointing } \\
\text { Device Apparatus } \\
\text { (IPDA) vs standard } \\
\text { mouse }\end{array}$ & $\begin{array}{l}\text { continuous } \\
\text { clicking, target } \\
\text { acquisition, } \\
\text { drag and drop }\end{array}$ \\
\hline
\end{tabular}

Measured \& predicted

information rate are not related for the $\mathrm{CP}$ subjects alone (although were for all subjects if considered as a group). After reprogramming of DynaVox (based on predictive model) 5/10 users showed improved information rate, but the group effect of reprogramming was not significant.

Chorded input faster and more accurate, with less errors than keyboard \& mouse

Success rate improved with predictive actions based on common access patterns. Nuances in the program required retraining prior to every use, thus participants with better memory were more successful.

No significant difference between modes, but automatic scanning was inferior for participants with spastic $\mathrm{CP}$ and step scanning poorest for those with athetoid CP

* MT greater for isometric joystick (582ms) compared to position joystick (430ms) $(p<0.001)$. Average MT and PD was proportional to CTD and inversely proportional to TD. MT was longest in upward D and shortest in downward D.

Group with standard mouse performed better than IPDA group for continuous clicking, yet both groups had similar 
Total $n$ (oth=other,

Age(s), Device/technique

Measures

Outcome

(CP)

$\begin{array}{llll}\text { Parker, } & \text { V - quasi- } & \text { severe dysarthria, } & \text { 6, CP=6, oth }=2(1 \\ 2006^{(48)} & \text { experimental } & \begin{array}{l}0-22 \% \text { on Frenchay } \\ \text { Dysartrhia }\end{array} & \text { CP+cerebral vascular } \\ & \text { Assessment } & \text { accident, 1 Multiple } \\ & & \text { sclerosis) }\end{array}$

adult Speech recognition software sclerosis)

$\begin{array}{lll}\text { Simpson, } & \text { IV - Before } & \text { severe physical } \\ 2006^{(45)} & \text { and after } & \text { disability } \\ & \text { group } & \\ & \text { comparison } & \end{array}$

14, $\mathrm{CP}=6, \mathrm{cntl}=8$

29-55 Adaptive

row/column scanning system (Input Device Agent (IDA)) vs self chosen scanning program; keyboard

\begin{tabular}{|c|c|c|c|c|c|c|c|}
\hline $\mathrm{Wu}, 2007^{(39)}$ & $\begin{array}{l}\text { V - quasi- } \\
\text { experimental }\end{array}$ & $\begin{array}{l}3 \mathrm{CP} \text { athetoid, } 2 \mathrm{CP} \\
\text { spastic, } 1 \mathrm{CP} \text { mixed }\end{array}$ & $6, C P=6$ & $6-10$ & $\begin{array}{l}\text { logitech mouse, } \\
\text { trackball, joystick }\end{array}$ & $\begin{array}{l}\text { Computerized } \\
\text { Assessment } \\
\text { Tool (CAT): } \\
\text { movement, } \\
\text { clicking and } \\
\text { dragging of } \\
\text { cursor }\end{array}$ & $\begin{array}{l}\text { Median success rate of } \\
\text { clicking: mouse } 6 \% \text {, } \\
\text { trackball } 17 \% \text {, joystick } \\
45 \% \text {; Median success } \\
\text { rate of pointing and } \\
\text { selecting: mouse } 6 \% \text {, } \\
\text { trackball } 17 \% \text {, joystick } \\
45 \% \text {; Median success } \\
\text { rate of dragging: mouse } \\
14 \%, \text { trackball } 7 \% \text {, } \\
\text { joystick } 31 \%\end{array}$ \\
\hline Yeh, $2008^{(31)}$ & $\begin{array}{l}\text { V - case } \\
\text { studies, } \\
\text { group } \\
\text { comparison }\end{array}$ & NS & $99, C P=49, \mathrm{cnt} l=50$ & NS & $\begin{array}{l}3 \text { projects: } \\
\text { Assessment } \\
\text { program; keyboard } \\
\text { adaptations; } \\
\text { pointing device } \\
\text { evaluation; on- } \\
\text { screen keyboards }\end{array}$ & $\begin{array}{l}\text { kinematic } \\
\text { parameters; } \\
\text { speed and } \\
\text { accuracy of } \\
\text { typing; travel } \\
\text { path, distance, } \\
\text { speed, } \\
\text { accuracy, } \\
\text { acceleration; } \\
\text { satisfaction }\end{array}$ & $\begin{array}{l}\text { Meeting the needs of } \\
\text { users through } \\
\text { assessment and } \\
\text { evaluation resulted in } \\
\text { increased speed, } \\
\text { accuracy and satisfaction } \\
\text { of device relative to a } \\
\text { standard keyboard or } \\
\text { mouse. }\end{array}$ \\
\hline
\end{tabular}

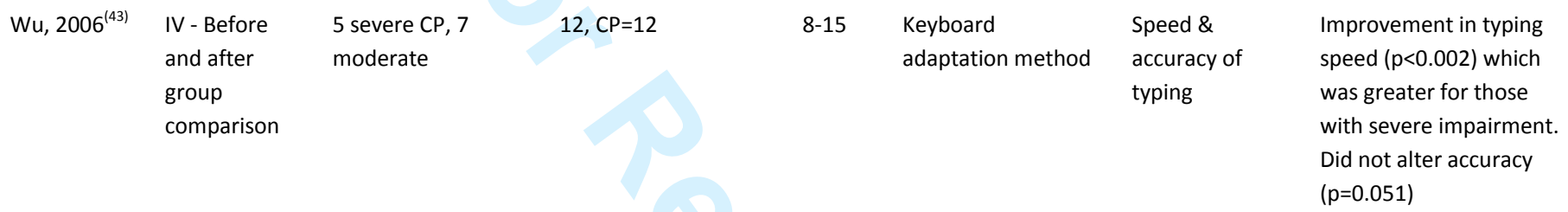
group typing speed $(p<0.002)$ which was greater for those with severe impairment. Did not alter accuracy $(p=0.051)$

character entry time, selection accuracy, timing errors, start scan time, row \& column press time

correct
computer
identification of
verbal

*7 participants completed training phase. 4/7 showed significant improvement in recognition of majority of target words. $3 / 7$ showed no change or negative effects

No significant difference between modes in any measures except that adaptive scanning system was $25.5 \%$ faster than self chosen scanning. Subjects achieved $90 \%$ accuracy and $15 \%$ timing errors with IDA.

Median success rate of 45\%; Median success rate of pointing and selecting: mouse $6 \%$, , joystick rate of dragging: mouse $14 \%$, trackball $7 \%$, joystick $31 \%$ typing; travel speed, satisfaction 
Table S2: Design and Testing of Algorithms to Improve Computer Recognition of Input.

\begin{tabular}{|c|c|c|c|c|c|c|c|}
\hline $\begin{array}{l}\text { Author, } \\
\text { year }\end{array}$ & $\begin{array}{l}\text { Research } \\
\text { Design }\end{array}$ & Participants & $\begin{array}{l}\text { Total } n \\
\text { (oth=other, cntl = } \\
\text { control) }\end{array}$ & $\begin{array}{l}\text { Age }(s), \\
\text { years } \\
(C P)\end{array}$ & Device/technique & Measures & Clinical Relevance \\
\hline
\end{tabular}

\begin{tabular}{|c|c|c|c|c|c|c|c|}
\hline $\begin{array}{l}\text { Yang, } \\
1998^{(28)}\end{array}$ & $\begin{array}{l}\text { V - case } \\
\text { study }\end{array}$ & $\begin{array}{l}\text { voluntary and } \\
\text { involuntary } \\
\text { movement }\end{array}$ & $1, C P=1$ & 14 & $\begin{array}{l}\text { Morse code } \\
\text { recognition - } \\
\text { variable degree } \\
\text { variable step size } \\
\text { least mean } \\
\text { squared } \\
\text { (VDVSLMS) } \\
\text { algorithm, } 2 \\
\text { variations of the } \\
\text { least mean } \\
\text { square (LMS) }\end{array}$ & $\begin{array}{l}\text { Character } \\
\text { recognition } \\
\text { rate }\end{array}$ & $\begin{array}{l}\text { Average matches (out of } 100 \text { ) } \\
\text { were } 23.5 \text { and } 69.7 \text { for } 2 \\
\text { variations of LMS algorithm } \\
\& 80.2 \text { for VDVSLMS } \\
\text { algorithm. The VDVSLMS } \\
\text { method had significantly } \\
\text { higher recognition rate } \\
(\alpha=0.05) \text {. }\end{array}$ \\
\hline $\begin{array}{l}\text { Fuh, } \\
2001^{(53)}\end{array}$ & $\begin{array}{l}\text { V - case } \\
\text { study }\end{array}$ & NS & $\begin{array}{l}3, \mathrm{CP}=1, \text { oth }=2 \text { (1 } \\
\text { upper limb } \\
\text { amputee, } 1 \\
\text { skilled expert) }\end{array}$ & teen & $\begin{array}{l}\text { algorithm, } \\
\text { Morse code } \\
\text { recognition - back } \\
\text { propagation } \\
\text { neural network } \\
\text { (BPN), } 2 \\
\text { variations of the } \\
\text { least mean } \\
\text { square (LMS) } \\
\text { algorithm }\end{array}$ & $\begin{array}{l}\text { Computer } \\
\text { recognition } \\
\text { rate }\end{array}$ & $\begin{array}{l}\text { By using new method can get } \\
96 \% \text { recognition rate with } \\
\text { neural network as opposed to } \\
\text { other methods ( } 12.6 \% \text { higher } \\
\text { than others) }\end{array}$ \\
\hline
\end{tabular}
$\begin{array}{lllllll}\begin{array}{l}\text { Morrison, } \\ 2002^{(54)}\end{array} & \begin{array}{l}\text { - quasi- } \\ \text { expermental }\end{array} & \begin{array}{l}\text { limited voluntary } \\ \text { muscle control }\end{array} & 1, \mathrm{CP}=1 & \text { NS } & \text { Hidden Markov } & \begin{array}{l}\text { Error rate } \\ \text { Number of training }\end{array} \\ \text { (\%) relative } & \text { examples/error rate, } 3 / 24 \%,\end{array}$

identify head and hand gestures

to number of training examples

$5 / 16 \%, 7 / 16 \%, 9 / 13 \%$.

Overall end-centered polar, end \& mean centered cartesian vectors had the lowest error rates $(9.5 \%$, $11 \%, 10 \%$ respectively) and head-centred Cartesian vectorhad the highest error rate $(40 \%)$.

7
8
9
1
2
3
4
5
6
7
8
9
50
51
52
53
5
5
56
57
58
5
60

Wu, $\quad V$-case $\quad$ -

$2002^{(55)} \quad$ study

NS

$\begin{array}{lll}\text { Yang, } & \text { IV - quasi- } \\ \text { 2004 }^{(30)} & \text { expermental } & \begin{array}{l}\text { Athetoid with } \\ \text { involuntary } \\ \text { movements }\end{array}\end{array}$

33, $\mathrm{CP}=2, \mathrm{cntl}=$ 14

15 , oth $=16(15$

skilled experts, 1

$\mathrm{SCl})$

2, $\mathrm{CP}=1$, oth $=1$ ( $1 \quad$ teen
skilled expert $)$

recognition -

fuzzy algorithms

(one-node \& long

short separation)

$\&$ adaptive

variable-ratio

threshold

prediction

(AVRTP)

algorithm

$\quad V$ - case

study
Athetoid with involuntary movements, delayed start on movements

$3, \mathrm{CP}=2$ oth $=1$
$(\mathrm{SCl})$

\section{Morse code
recognition -}

counter

propagation

network with

variable degree

variable step size

LMS

(CPNVDVSSLMS)

2 variations of

the LMS

algorithm

Morse code recognition fuzzy support vector machines (FSVM), learning vector quantization

(LVQ), 2 variations of the LMS algorithm
Recognition Recognition rate for 3 rate algorithms: AVRTP: 94.0\%, one-node $98.0 \%$, long-short $99.1 \%$. Variation for the individual with CP was $10 \%$ higher on long signals, and $40 \%$ higher on short signals.

Character Average matches (out of 100) recognition were 22.2 and 71.4 for 2 rate variations of LMS algorithm \& 81.9 for CPNVDVSLMS algorithm. The CPNVDVSLMS method had significantly higher recognition rate $(a=0.05)$.

$\begin{array}{ll}\begin{array}{ll}\text { Character } \\ \text { recognition }\end{array} & \text { Average matches (out of 100) } \\ \text { rate } & \text { were 22.2 and 71.4 for } 2 \\ & \text { variations of LMS algorithm, } \\ & 77.5 \text { for LVQ \& 84.8 for FSVM } \\ & \text { algorithm. The FSVM method } \\ & \text { had significantly higher } \\ & \text { recognition rate (a=0.05) } \\ & \text { than other 3 methods. }\end{array}$




\begin{tabular}{|c|c|c|c|c|c|c|c|}
\hline $\begin{array}{l}\text { Olds, } \\
2008^{(26)}\end{array}$ & $\begin{array}{l}\text { V - quasi- } \\
\text { expermental }\end{array}$ & athetoid & $3, \mathrm{CP}=3$ & $24-49$ & $\begin{array}{l}\text { Two stage filter } \\
\text { model to predict } \\
\text { icon clicking }\end{array}$ & $\begin{array}{l}\text { target } \\
\text { acquisition } \\
\text { rate, } \\
\text { success rate }\end{array}$ & $\begin{array}{l}\text { Target acquisition rate: } \text { with } \\
\text { model }=9.6 \mathrm{~s}, \text { with filter }= \\
3.5 \mathrm{~s} \text {, Success rate: } \text { with } \\
\text { model }=79 \% \text {, with filter } 99 \%\end{array}$ \\
\hline
\end{tabular}

